\title{
Prevalence and the Determinants of Traditional, Complementary, and Integrative Medicine Use Among Breastfeeding Mothers in Shiraz, Iran: a Cross-section Study
}

Hossein Molavi Vardanjani

Shiraz University of Medical Sciences

Zahra Salehi

Shiraz University of Medical Sciences

Faranak Alembizar

Shiraz University of Medical Sciences

Holger Cramer

University of Duisburg-Essen: Universitat Duisburg-Essen

Mehdi Pasalar ( $\nabla$ pasalar@sums.ac.ir)

Shiraz University of Medical Sciences https://orcid.org/0000-0003-2458-2626

\section{Research Article}

Keywords: Herbal medicine, Galactagogues, Breastfeeding, Lactation, Iran

Posted Date: May 17th, 2021

DOI: https://doi.org/10.21203/rs.3.rs-508776/v1

License: (c) (1) This work is licensed under a Creative Commons Attribution 4.0 International License.

Read Full License 


\section{Abstract}

Background: Breastfeeding is highly important for a child's health, and the widespread use of herbal medicines as galactagogues has been reported. The present study was conducted to evaluate the use of traditional, complementary, and integrative medicine (TCIM) and its determinants among breastfeeding mothers in Shiraz, Iran.

Methods: In this cross-sectional study, mothers over 18 years who referred to neonatal clinics affiliated to Shiraz University of Medical Sciences were enrolled. Using a structured interview, we explored the prevalence and of the use of TCIM products and its associated factors.

Results: Out of 625 mothers who were approached, 483 agreed to participate (response rate: $77.3 \%$ ). The average age was $27.3 \pm 5.9$ years. The prevalence of using TCIM products during current breastfeeding was $97.1 \%$. There were 168 working mothers (44.9\%); 163 mothers $(34.1 \%)$ complaining of postpartum breastfeeding problems, and 327 mothers $(68 \%)$ had no past history of breastfeeding. Recommendations of medical staff or relatives were the most frequent reasons for the consumption of TCIM products (64.9\%). Only $27 \%$ of mothers disclosed the use of TCIM products to their doctor or healthcare provider, although $62 \%$ of mothers were asked about the use of such products. Notably, 438 mothers $(95.8 \%)$ considered TCIM to increase their milk. Based on multivariable logistic regression, literacy and past use of TCIM galactagogues were independently associated with TCIM products use.

Conclusions: The use of TCIM galactagogues is highly common among breastfeeding mothers in south of Iran, showing a diverse range of determinants. It is necessary to evaluate the safety and efficacy of common herbal galactagogues, and evidence-based studies must be designed to achieve standardized complementary medicine approaches in this regard.

\section{Background}

Breast milk is the ideal food for infants, providing various benefits to both the mother and child [1,2]. The World Health Organization (WHO) vehemently supports breastfeeding, recommending its continuation for a minimum of 24 months as it is an important right of the mother and infant and improves their health [3]. Breast milk contains a variety of vitamins, minerals, proteins, and unsaturated fatty acids, and is rich in antimicrobial, anti-inflammatory and immunomodulatory compounds [4,5]. Hence, it reduces the infant's risk of acquiring certain gastrointestinal, respiratory, and infectious diseases. It also has beneficial effects on the cardiac, neurological, endocrine, and immune function of the infant [6, 7]. For the mother, breastfeeding is associated with a reduced risk of breast, endometrial, and ovarian cancer, as well as decreased bleeding and accelerated return of the uterus to its original condition [8].

Various factors affect the duration of a mother's breastfeeding, including the education level, economic status, family support, and family stability. Other influential factors are breastfeeding skills and maternal knowledge in this regard. Despite its importance, breastfeeding is discontinued for a variety of reasons, including fatigue, problems with breastfeeding techniques, and not having enough milk [9]. Early onset of 
complementary foods following weaning the child from breastfeeding can cause complications such as malnutrition, obesity, and allergies, while increasing the risk of gastrointestinal, respiratory, and infectious diseases in the newborn $[1,10]$. On the other hand, not having enough milk can decrease the mother's confidence and give rise to mental health problems [11].

The use of traditional, complementary, and integrative medicine (TCIM) has been expanding in the past decade globally [12]. According to reports of the WHO, a considerable number of herbal compounds and dietary supplements are used by people in both developed and developing countries [13]. If applied properly, TCIM can help meet the needs of breastfeeding mothers and can guide them toward successful breastfeeding [14]. In TCIM, there are several ways to increase the mother's milk, including acupuncture, massage, kangaroo mother care, relaxation, and herbal medicine [15]. The use of herbal products represents one of the prime aspects of TCIM, with the promotion of lactation being one of the key applications of such products $[16,17]$. Galactagogues are foods, herbs, or medications that support the initiation, continuation, or reinforcement of breastfeeding [18]. Notably, mothers often choose to use herbal supplements because they believe that they are safer, more reliable, and cheaper than chemical drugs $[18,19]$. Many foods and medicines have lactation-inducing properties, with the choice of fruits, foods, and herbs consumed for this purpose varying from country to country $[17,20]$.

In addition to the effect of plants on milk quantity, their effect on milk quality is also important. Plants induce changes in the process of breastfeeding by altering the color, smell, taste, and quality of milk [19, 21]. In Iran, breastfeeding has been known to people since long ago, with Avicenna mentioning this issue in The Canon of Medicine in the 10th century [22]. In Persian Medicine (PM), the greatest determinant of milk production is regarded as the production of high-quality blood humor, making proper nutrition highly influential in increasing the mother's breast milk. In PM, lactating mothers are recommended to refrain from consuming certain plants in large volumes or for prolonged periods, some examples of which are garlic, onion, and lentils. This is because such plants can alter the quality of milk [23-25].

Despite the crucial roles of breast milk in the child's health and all-round development (especially during the first six months of life), it is possible that the mother discontinues breastfeeding, particularly due to not having enough milk [26]. Although various plant and food products are used by breastfeeding mothers in Iran, the precise range of compounds used is yet to be delineated in Shiraz, Iran. Meanwhile, despite the importance of the provision of appropriate TCIM prescriptions by medical staff, most breastfeeding mothers opt for self-medication when taking up TCIM [12]. Therefore, the present study was conducted to assess the prevalence of TCIM use and its determining factors among breastfeeding mothers in an urban area in southern Iran.

\section{Methods}

A cross-sectional study was conducted in the autumn of 2020 in Shiraz, Fars, Iran. The city of Shiraz is the most populous urban area in southern Iran, hosting a population of approximately two million people. According to the latest statistics of Shiraz University of Medical Sciences, the demographic 
characteristics of women in Shiraz is as follows: literacy rate: $91.4 \%$; employment rate: $64.6 \%$; gender ratio (male/female): 0.98 ; proportion married: $75.1 \%$; proportion in reproductive years: $59.8 \%$; predominant ethnicity: Persian; official language: Persian; predominant religion: Muslim (Shia).

\section{Study population}

Mothers aged 18 years or more who were willing to breastfeed their child, who was aged between 0 to 24 months, were eligible for inclusion in the study. Mothers who lived outside Shiraz, lacked the ability to speak in Persian, or were pregnant were excluded. We also excluded mothers with systemic diseases (hypoglycemia, hypothyroidism, hyperthyroidism, uncontrolled blood pressure, etc.) or liver diseases (severe fatty liver, cirrhosis, etc.).

The sample size was calculated using the formula of Cochran for prevalence studies. We assumed the prevalence of using herbal galactagogues to be $15 \%$, with a first type error of $5 \%$ and a prevalence estimation accuracy of $20 \%$. The response rate was considered to be $85 \%$. Based on these assumptions, the sample size required was estimated to include 625 people.

Sampling was done using the multi-stage random cluster sampling technique. First, in each of the 10 urban regions of Shiraz, we determined and selected the central government facility providing mother and child health services. Then, we proceeded with sampling during all working hours and days at the selected centers for two months. All eligible mothers who referred to the centers were first acquainted with the study and its objectives before being invited to participate. Ultimately, mothers who expressed informed consent were interviewed.

\section{Data collection}

Data were collected using a structured interview based on a researcher-made questionnaire. Initially, a conceptual framework was designed based on a review of the literature and group discussion sessions. This conceptual structure included the mothers' views on the use of TCIM compounds in reinforcing breastfeeding, their experiences with the use of TCIM, common compounds used by breastfeeding mothers, reasons and factors that facilitate the use of TCIM compounds, and the mothers' interactions with mother and infant health service providers regarding the use of TCIM products. A team consisting of a PM specialist, a gynecologist/obstetrician, a pediatrician, and a methodologist was formed, with each member being asked to design questions for each component of the conceptual framework. A total of 80 questions were designed, 27 of which were selected for the final questionnaire after multiple group discussions. The questionnaire included seven sections, namely demographic data (age, education, occupation, monthly income and expenses, place of residence, and ethnicity), information related to pregnancy, delivery, and breastfeeding (number of pregnancies, duration of current breastfeeding, history of abortion, birth order, breastfeeding problems, history of breastfeeding, duration of previous breastfeeding, history of using TCIM compounds in previous breastfeeding, number of mother and child health services received, and use of formula feeding), and five other components of the conceptual framework. The content and face validity of the questionnaire were assessed by seven experts form the 
related disciplines, and the suggested corrections were made when deemed appropriate. Then, a pilot questionnaire was used to collect data from 15 breastfeeding mothers to detect and resolve any problems. Ultimately, the final questionnaire consisted of 25 multiple choice (Likert scale), yes/no, or short answer questions. To evaluate the reliability of the questionnaire, the test-retest method was used where 30 breastfeeding mothers aged 18 to 40 years were interviewed twice with a two-week interval between the interviews. Among the questions, the lowest test-retest correlation coefficient obtained was 0.84 with a P-value of above 0.001 . The reliability of the questionnaire was also assessed using Cronbach's alpha, which was found to be equal to 0.79 .

The interviews were conducted by 10 trained midwives working in the selected mother and child healthcare centers. The interviews lasted for an average of 15 minutes and were conducted in a private room at each center.

\section{Statistical analysis}

Data was cleaned and prepared. Descriptive statistics including mean, standard deviation (SD), frequency and relative frequency (\%) were estimated and presented to describe the data. Two independent sample test was applied to univariate analysis of the association of continues predictors with the study outcome. Fisher exact or Chi-square tests were applied for univariate analysis of the association of categorical variables with the TCIM use.

Multivariable binary logistic regression modeling was applied to estimate the adjusted odds ratio (OR) and their $95 \%$ confidence interval $(\mathrm{Cl})$ as the measure of independent association of the studied variables with the TCIM use. Variable selection was performed based on a univariate p-value of less than 0.3. Stepwise modeling technique was applied. A p-value of less than 0.05 indicated statistical significance. Data analysis was done by using Stata software (Release 11.2, College Station, TX: Stata Corp LLC).

\section{Ethical considerations}

The study protocol was based on the Declaration of Helsinki for Medical Research Involving Human Subjects. Prior to commencing the research, the protocol was approved by the Ethics Committee of Shiraz University of Medical Sciences (IR.SUMS.REC.1397.1020). Women who willingly signed the written consent forms were enrolled into the study.

\section{Results}

Out of 625 breastfeeding mothers who asked to participate, 483 mothers participated in the study (response rate $=77.3 \%)$ The mean age of the participants was $28.1 \pm 5.6$ years. Roughly $63 \%(n=300)$ had of university education and about $79 \%(n=360)$ were residents of urban areas. Approximately $35.4 \%$ $(n=164)$ of mothers worked outside the home. The prevalence of TCIM usage was calculated as $91.7 \%$ (95\% Cl: $88.8 \%$ - 93.8\%), with the age-standardized prevalence (ASP) being $52.1 \%$ (95\% Cl: $50.1 \%-$ $54.1 \%)$ (Table 1). 
Table 1

Socio-Demographic and background characteristics associated with use of traditional, complementary, and integrative medicine (TCIM) products

\begin{tabular}{|c|c|c|c|c|}
\hline Characteristics & $\begin{array}{l}\text { TCIM } \\
\text { User } \\
\text { n (\%) }\end{array}$ & $\begin{array}{l}\text { TCIM Non- } \\
\text { user } \\
\text { n (\%) }\end{array}$ & $\begin{array}{l}\text { Total } \\
\text { n (\%) }\end{array}$ & $\begin{array}{l}\mathrm{p}- \\
\text { value }\end{array}$ \\
\hline Age (year) & & & & 0.048 \\
\hline mean \pm standard deviation & $\begin{array}{l}28.2 \pm \\
5.5\end{array}$ & $26.4 \pm 6.3$ & $\begin{array}{l}483 \\
(100)\end{array}$ & \\
\hline Education level & & & & $<001$ \\
\hline Illiterate & $2(0.5)$ & $4(10.2)$ & $6(1.3)$ & \\
\hline Diploma or below diploma & $\begin{array}{l}153 \\
(35.3)\end{array}$ & $14(35.9)$ & $\begin{array}{l}167 \\
(35.3)\end{array}$ & \\
\hline Academic level & $\begin{array}{l}279 \\
(64.2)\end{array}$ & $21(53.9)$ & $\begin{array}{l}300 \\
(63.4)\end{array}$ & \\
\hline Living place & & & & 0.955 \\
\hline Urban & $\begin{array}{l}331 \\
(78.8)\end{array}$ & $29(78.4)$ & $\begin{array}{l}360 \\
(78.8)\end{array}$ & \\
\hline Rural & $\begin{array}{l}89 \\
(21.2)\end{array}$ & $8(21.6)$ & $\begin{array}{l}97 \\
(21.2)\end{array}$ & \\
\hline Ethnicity & & & & $<$ \\
\hline Fars & $\begin{array}{l}296 \\
(68.8)\end{array}$ & $24(63.2)$ & $\begin{array}{l}320 \\
(68.4)\end{array}$ & \\
\hline Others (Minorities) & $\begin{array}{l}134 \\
(31.2)\end{array}$ & $14(36.8)$ & $\begin{array}{l}148 \\
(31.6)\end{array}$ & \\
\hline Employment status & & & & 0.189 \\
\hline Employed & $\begin{array}{l}159 \\
(36.6)\end{array}$ & $9(22.5)$ & $\begin{array}{l}168 \\
(35.4)\end{array}$ & \\
\hline Housewife & $\begin{array}{l}275 \\
(63.4)\end{array}$ & $31(77.5)$ & $\begin{array}{l}306 \\
(64.6)\end{array}$ & \\
\hline Monthly income(Rank) & & & & 0.001 \\
\hline Low & $24(5.5)$ & $8(20.0)$ & $32(6.7)$ & \\
\hline Middle & $\begin{array}{l}191 \\
(43.5)\end{array}$ & $11(27.5)$ & $\begin{array}{l}202 \\
(42.0)\end{array}$ & \\
\hline high & $\begin{array}{l}223 \\
(51.0)\end{array}$ & $21(52.5)$ & $\begin{array}{l}246 \\
(51.3)\end{array}$ & \\
\hline
\end{tabular}




\begin{tabular}{|c|c|c|c|c|}
\hline Characteristics & $\begin{array}{l}\text { TCIM } \\
\text { User } \\
\text { n (\%) }\end{array}$ & $\begin{array}{l}\text { TCIM Non- } \\
\text { user } \\
\text { n (\%) }\end{array}$ & $\begin{array}{l}\text { Total } \\
\text { n (\%) }\end{array}$ & $\begin{array}{l}\mathrm{p}- \\
\text { value }\end{array}$ \\
\hline Cost-Income matching & & & & 0.391 \\
\hline Yes & $\begin{array}{l}153 \\
(35.0)\end{array}$ & $11(28.2)$ & $\begin{array}{l}164 \\
(34.5)\end{array}$ & \\
\hline No & $\begin{array}{l}284 \\
(65.0)\end{array}$ & $28(71.8)$ & $\begin{array}{l}312 \\
(65.5)\end{array}$ & \\
\hline Infants' Birth order & & & & 0.002 \\
\hline First & $\begin{array}{l}245 \\
(63.0)\end{array}$ & $28(80.0)$ & $\begin{array}{l}273 \\
(64.4)\end{array}$ & \\
\hline Other & $\begin{array}{l}144 \\
(37.0)\end{array}$ & $7(20.0)$ & $\begin{array}{l}151 \\
(35.6)\end{array}$ & \\
\hline Parity & & & & 0.028 \\
\hline One & $\begin{array}{l}222 \\
(51.2)\end{array}$ & $22(55.0)$ & $\begin{array}{l}244 \\
(51.5)\end{array}$ & \\
\hline second & $\begin{array}{l}149 \\
(34.3)\end{array}$ & $13(32.5)$ & $\begin{array}{l}162 \\
(34.2)\end{array}$ & \\
\hline More & $\begin{array}{l}63 \\
(14.5)\end{array}$ & $5(12.5)$ & $\begin{array}{l}68 \\
(14.3)\end{array}$ & \\
\hline History of Abortion & & & & 0.047 \\
\hline One & $\begin{array}{l}63 \\
(36.2)\end{array}$ & $10(62.5)$ & $\begin{array}{l}73 \\
(38.4)\end{array}$ & \\
\hline Two or more & $8(4.6)$ & $2(12.5)$ & $\begin{array}{l}10 \\
(38.4)\end{array}$ & \\
\hline No & $\begin{array}{l}103 \\
(59.2)\end{array}$ & $4(25.0)$ & $\begin{array}{l}107 \\
(56.2)\end{array}$ & \\
\hline Lactation problem in the current breastfeeding & & & & 0.916 \\
\hline Yes & $\begin{array}{l}150 \\
(34.2)\end{array}$ & $13(33.3)$ & $\begin{array}{l}163 \\
(34.1)\end{array}$ & \\
\hline No & $\begin{array}{l}289 \\
(65.8)\end{array}$ & $26(66.7)$ & $\begin{array}{l}315 \\
(65.9)\end{array}$ & \\
\hline History of breastfeeding & & & & 0.016 \\
\hline Yes & $\begin{array}{l}148 \\
(96.1)\end{array}$ & $6(3.9)$ & $\begin{array}{l}154 \\
(32.0)\end{array}$ & \\
\hline No & $\begin{array}{l}293 \\
(89.6)\end{array}$ & $34(10.4)$ & $\begin{array}{l}327 \\
(68.0)\end{array}$ & \\
\hline
\end{tabular}




\begin{tabular}{|c|c|c|c|c|}
\hline Characteristics & $\begin{array}{l}\text { TCIM } \\
\text { User } \\
\text { n (\%) }\end{array}$ & $\begin{array}{l}\text { TCIM Non- } \\
\text { user } \\
\text { n (\%) }\end{array}$ & $\begin{array}{l}\text { Total } \\
\text { n (\%) }\end{array}$ & $\begin{array}{l}\text { p- } \\
\text { value }\end{array}$ \\
\hline Duration of previous breastfeeding (month) & & & & 0.022 \\
\hline Mean \pm standard deviation & $\begin{array}{l}6.3 \pm \\
8.9\end{array}$ & $3.0 \pm 7.3$ & $\begin{array}{l}483 \\
(100)\end{array}$ & \\
\hline Neonatal care visits received (number) & & & & 0.370 \\
\hline Mean \pm standard deviation & $\begin{array}{l}1.2 \pm \\
0.9\end{array}$ & $1.1 \pm 1.0$ & $\begin{array}{l}483 \\
(100)\end{array}$ & \\
\hline History of consumption of TCIM products & & & & 0.009 \\
\hline Yes & $\begin{array}{l}130 \\
(97.7)\end{array}$ & $3(2.3)$ & $\begin{array}{l}133 \\
(31.4)\end{array}$ & \\
\hline No & $\begin{array}{l}263 \\
(90.7)\end{array}$ & $27(9.3)$ & $\begin{array}{l}290 \\
(68.6)\end{array}$ & \\
\hline $\begin{array}{l}\text { History of consumption of TCIM products in previous } \\
\text { breastfeeding }\end{array}$ & & & & 0.016 \\
\hline Yes & $\begin{array}{l}93 \\
(97.9)\end{array}$ & $2(2.1)$ & $\begin{array}{l}95 \\
(19.8)\end{array}$ & \\
\hline No & $\begin{array}{l}347 \\
(90.4)\end{array}$ & $37(9.6)$ & $\begin{array}{l}384 \\
(80.2)\end{array}$ & \\
\hline Do you feed your child with formula too? & & & & 0.823 \\
\hline Yes & $\begin{array}{l}228 \\
(91.9)\end{array}$ & $20(8.1)$ & $\begin{array}{l}248 \\
(53.0)\end{array}$ & \\
\hline No & $\begin{array}{l}201 \\
(91.4)\end{array}$ & $19(8.6)$ & $\begin{array}{l}220 \\
(47.0)\end{array}$ & \\
\hline Do you have access to TCIM products easily? & & & & 0.001 \\
\hline Yes & $\begin{array}{l}399 \\
(93.2)\end{array}$ & $29(6.8)$ & $\begin{array}{l}428 \\
(89.4)\end{array}$ & \\
\hline No & $\begin{array}{l}41 \\
(80.0)\end{array}$ & $10(20.0)$ & $\begin{array}{l}51 \\
(10.6)\end{array}$ & \\
\hline
\end{tabular}

Notably, $90 \%$ of mothers who had a positive past experience with the use of TCIM galactagogues reported current use of these products. Out of mothers who used TCIM to improve their breastfeeding, $75.6 \%(n=317)$ believed that these compounds could be recommended to others. This figure was $62.5 \%$ $(n=25)$ among mothers who were not current users of TCIM galactagogues $(P=0.068)$. From the 
mothers who used TCIM products to improve lactation, 52.0\% $(n=230)$ believed that these products have at least minimal side effects (Table 2). 
Table 2

Participants' viewpoints and experiences about the traditional, complementary, and integrative medicine (TCIM) and chemical drugs

\begin{tabular}{|c|c|c|c|}
\hline Viewpoint or Experience & $\begin{array}{l}\text { TCIM user } \\
\text { n (\%) }\end{array}$ & $\begin{array}{l}\text { TCIM Non- } \\
\text { user } n \text { (\%) }\end{array}$ & $\begin{array}{l}\text { p- } \\
\text { value }\end{array}$ \\
\hline $\begin{array}{l}\text { Do you think TCIM products are effective to increase breast } \\
\text { milk? }\end{array}$ & & & \multirow[t]{3}{*}{0.003} \\
\hline Yes & $\begin{array}{l}404 \\
(97.8)\end{array}$ & $34(89.5)$ & \\
\hline No & $9(2.2)$ & $4(10.5)$ & \\
\hline \multicolumn{3}{|l|}{ Are TCIM products recommendable to all lactating mothers? } & \multirow[t]{3}{*}{0.068} \\
\hline Yes & $\begin{array}{l}317 \\
(75.6)\end{array}$ & $25(62.5)$ & \\
\hline No & $\begin{array}{l}102 \\
(24.4)\end{array}$ & $15(37.5)$ & \\
\hline \multicolumn{3}{|l|}{ Do you have any experience of healing by TCIM products? } & \multirow{3}{*}{$\begin{array}{l}<.001 \\
0.00\end{array}$} \\
\hline Yes & $\begin{array}{l}395 \\
(90.0)\end{array}$ & $26(65.0)$ & \\
\hline No & $44(10.0)$ & $14(35.0)$ & \\
\hline \multicolumn{3}{|l|}{ What do you think about side effects of TCIM products? } & \multirow[t]{6}{*}{0.517} \\
\hline No side effect & $\begin{array}{l}172 \\
(39.0)\end{array}$ & $17(43.6)$ & \\
\hline Minor side effect & $\begin{array}{l}229 \\
(51.9)\end{array}$ & $16(41.0)$ & \\
\hline Major side effects & $2(0.5)$ & $0(0.0)$ & \\
\hline Life-threating side effects & $1(0.2)$ & $0(0.0)$ & \\
\hline I don't know & $37(8.4)$ & $6(15.4)$ & \\
\hline \multicolumn{3}{|l|}{ What do you think about side effects of chemical drugs? } & \multirow[t]{6}{*}{0.040} \\
\hline No side effect & $1(0.2)$ & $1(2.6)$ & \\
\hline Minor side effect & $42(9.5)$ & $6(15.4)$ & \\
\hline Major side effects & $\begin{array}{l}193 \\
(43.8)\end{array}$ & $11(28.2)$ & \\
\hline Life-threating side effects & $\begin{array}{l}152 \\
(34.47)\end{array}$ & 13(33.3) & \\
\hline I don't know & $53(12.0)$ & $8(20.5)$ & \\
\hline
\end{tabular}




\begin{tabular}{|c|c|c|c|}
\hline Viewpoint or Experience & $\begin{array}{l}\text { TCIM user } \\
\text { n (\%) }\end{array}$ & $\begin{array}{l}\text { TCIM Non- } \\
\text { user } n(\%)\end{array}$ & $\begin{array}{l}\mathrm{p}- \\
\text { value }\end{array}$ \\
\hline $\begin{array}{l}\text { What do you think about concomitant consumption of TCIM } \\
\text { products and chemical drugs? }\end{array}$ & & & 0.357 \\
\hline Synergistic effects & $\begin{array}{l}130 \\
(29.5)\end{array}$ & $10(25.6)$ & \\
\hline Results in side effects & $\begin{array}{l}182 \\
(41.3)\end{array}$ & $15(38.5$ & \\
\hline Antagonistic effects & $31(7.0)$ & $1(2.6)$ & \\
\hline None & $98(22.2)$ & 13(33.3) & \\
\hline $\begin{array}{l}\text { Were galactagogue TCIM products effective in your } \\
\text { experience? }\end{array}$ & & & NA \\
\hline Absolutely & $\begin{array}{l}259 \\
(59.5)\end{array}$ & NA & \\
\hline Partially & $\begin{array}{l}149 \\
(33.8)\end{array}$ & NA & \\
\hline Not at all & $27(6.2)$ & NA & \\
\hline Have negative effect & $2(0.5)$ & NA & \\
\hline \multicolumn{4}{|l|}{ Were galactagogue TCIM products safe in your experience? } \\
\hline Yes & $\begin{array}{l}421 \\
(99.8)\end{array}$ & NA & NA \\
\hline No & $1(0.2)$ & NA & \\
\hline $\begin{array}{l}\text { Do you recommend galactagogue TCIM products to other } \\
\text { mothers? }\end{array}$ & & & 0.002 \\
\hline Yes & $\begin{array}{l}177 \\
(40.1)\end{array}$ & $6(15.0)$ & \\
\hline No & $\begin{array}{l}264 \\
(59.9)\end{array}$ & $34(85.0)$ & \\
\hline Why did you use TCIM products during your breastfeeding? & & & NA \\
\hline As Galactagogue & $\begin{array}{l}390 \\
(66.4)^{*}\end{array}$ & NA & \\
\hline Child's agitation & $23(4.0)$ & NA & \\
\hline Child's jaundice & $\begin{array}{l}124 \\
(21.1)\end{array}$ & NA & \\
\hline Child's sleeplessness & $35(6.0)$ & NA & \\
\hline Other & $15(2.6)$ & NA & \\
\hline
\end{tabular}


* Percentages was calculated based on the cumulative response numbers, as some mothers reported more than one TCIM products used during their breastfeeding period.

The prime reason for taking up the use of TCIM galactagogues was recommendations by relatives (64.9\%) and medical staff (64.9\%). On the other hand, the low cost of TCIM compounds was the least common reason for choosing to use such compounds among mothers who used TCIM (Fig. 1).

According to the self-reported data from mothers participating in the study, natural products that were consumed for more than 10 days and in large quantities to induce lactation during breastfeeding included lentils $(31.8 \% ; n=54)$, coffee $(25.9 \% ; n=44)$, fresh parsley $(15.9 \% ; n=27)$, garlic/onion $(4.7 \% ; n$ $=8)$, barley $(15.9 \% ; n=27)$, lemon juice $(3.5 \% ; n=6)$, and senna leaf $(2.4 \% ; n=4)$. Interestingly, $62 \%$ of medical staff had asked mothers regarding the history of using TCIM while visiting medical centers, with $73 \%$ of mothers refraining from disclosing their TCIM use to their healthcare provider (Fig. 2).

The highest prevalence of usage was related to iron supplementation (24\%) and herbal galactagogue drops (21\%), while the lowest prevalence was related to folic acid (1\%) (Fig. 3).

Based on multivariable logistic regression analysis, the likelihood of TCIM use among illiterate mothers was $96 \%$ lower relative to literate mothers (OR: $0.04,95 \% \mathrm{Cl}: 0.006,0.32$ ). Moreover, the prevalence of TCIM usage among mothers who did not have a history of its usage was about $80 \%$ lower than mothers who reported a positive past usage (Table 3 ).

Table 3

Associated factors with traditional, complementary, and integrative medicine (TCIM) use among Iranian Lactating mothers, 2020

\begin{tabular}{|lll|}
\hline Factor & Crude OR (95\% Cl) & Adjusted OR (95\% Cl) \\
\hline Illiteracy & $0.15(0.05,0.46)$ & $0.04(0.006,0.32)$ \\
\hline Rural Residency & $1.02(0.46,2.23)$ & $3.09(0.78,9.79)$ \\
\hline Employment & $0.49(0.24,1.02)$ & $0.26(0.09,0.77)$ \\
\hline Higher Monthly Costs & $1.00(1.00,1.00)$ & $1.82(0.66,5.02)$ \\
\hline Higher No. of Parity & $0.99(0.68,1.44)$ & $0.38(0.21,0.71)$ \\
\hline History of Lactation & $1.39(0.93,2.07)$ & $1.63(1.02,2.63)$ \\
\hline Longer Duration of Breast Feeding & $1.06(1.01,1.11)$ & $1.09(1.00,1.17)$ \\
\hline Lack of History of TCIM Use & $0.23(0.07,0.75)$ & $0.21(.05,0.94)$ \\
\hline Abbreviations: OR, odds ratio; Cl, confidence interval & \\
\hline
\end{tabular}




\section{Discussion}

In this study, a significant percentage of mothers (97.1\%) had used TCIM during breastfeeding, which is higher than the percentage of complementary medicine use in Australia (59.9\%), China (45\%), Taiwan (87.7\%), USA (16\%) and Sierra Leone (37\%), but is close to the results reported in Italy (97.3\%) $[16,19,21$, $25,27,28]$. Of course, if we consider the ASP, this rate $(52.1 \%)$ will be very close to the results of Australia and China. Perhaps one of the reasons for the difference to the results of countries such as Taiwan or Sierra Leone is the lack of using the ASP index. Therefore, to facilitate comparison of prevalence indicators among different communities, standardization based on the ASP is suggested.

The rate of TCIM uses varies from country to country [29]. This may be due to variations in study design (sampling technique, inclusion/exclusion criteria, etc.), differences among individuals living in different communities (cultural, economic, etc.), or variations in herbal medicine species deepening on the native vegetation of each country. As a result, the availability and popularity of TCIM compounds varies between countries.

In this study, the main reason for using TCIM among breastfeeding was to induce lactation (66.4\%). However, in Italy and Sierra Leone, mothers often used TCIM for other reasons, with only $2.8 \%$ and $2.1 \%$ of them using TCIM to induce lactation, respectively $[16,28]$. This figure was lower in Iran even compared with Australia, where more than half of mothers (60.4\%) used complementary medicine to increase their milk. The high use of TCIM galactagogues in our study could be due to religious beliefs and the emphasis of Islam on breastfeeding [30]. Support for working mothers and national breastfeeding promotion programs in Iran [31] may also contribute toward continuing breastfeeding and making use of TCIM galactagogues.

In our study, $64.2 \%$ of mothers who used TCIM had received academic education. This figure is lower relative to the United States (81\%) and Macau (87\%), but higher compared with Sierra Leone $(5.7 \%)$ and Malaysia (18.1\%) [16, 25, 32, 33]. A number of recent studies have shown a positive association between higher education and increased TCIM usage [34]. It is possible that with higher education, a greater awareness of the benefits and risks of TCIM is achieved, resulting in increased rational use of TCIM products. In the present study, multivariable regression analysis also showed a much higher prevalence of TCIM usage among breastfeeding mothers with higher education relative to those with lower education.

Interestingly, we found that $36.6 \%$ of breastfeeding mothers using TCIM were employed, which is less than the figures reported in the United States (56\%), Malaysia (89.2\%), and Sierra Leone (52.1\%) [16, 25, 33]. On the other hand, our multivariable regression analysis showed that working mothers used TCIM about $75 \%$ less than housewives. Perhaps one of the reasons behind this difference is the lack of referral of working mothers to medical centers due to employment and less opportunity for regular follow-ups. If this is the case, local health systems must work toward raising awareness about the risks of missing regular maternity follow-ups. 
In our study, as in similar research conducted in Taiwan and Australia, the mothers were predominantly primiparous $(64.4 \%)[2,27]$. This may be explained by a higher rate of referrals among women in this group due to less experience concerning the breastfeeding process. Notably, $65.8 \%$ of mothers who had used TCIM did not have breastfeeding problems. The high rate of TCIM usage (97.1\%) in this group may be due to the effect of advertisements regarding the use of galactagogues or the mothers' desire to boost their milk quality and achieve better infant weight gain.

In our study, most recommendations regarding TCIM usage came from relatives and medical staff (general practitioners and midwives). The extent to which Iranian physicians prescribe TCIM products and consider them to be effective has been investigated in prior studies [35]. In comparison, the highest proportion of recommendations regarding the use of complementary medicine came from friends in the Malaysian study (60\%) and from family in the Australian study (61.5\%), showing consistency with our data [2, 33]. In Italy, however, obstetricians/gynecologists made the most TCIM recommendations (44\%) [28]. Belief in the effectiveness of complementary medicine (43.1\%), in the harm of chemical drugs $(28.1 \%)$, and in the safety of TCIM $(27 \%)$ were other factors contributing to high rate of TCIM use seen in our study. In Sierra Leone, the affordability, availability, effectiveness, and safety of TCIM products contributed to their usage [16]. In the Malaysian study, most mothers (65\%) chose herbal galactagogues because of their natural components [33]. Attention to these factors and planning to provide correct information to breastfeeding mothers should be prioritized by infant health planners at the national and regional levels.

One substantial finding of the present study is that most breastfeeding mothers (73\%) were reluctant to report the use of TCIM compounds to medical staff. In line with this finding, $88.6 \%$ of mothers did not report TCIM treatments in Sierra Leone, mostly because they deemed it to be unnecessary [16]. Also, in our study, only $62 \%$ of the medical staff had asked regarding the history of TCIM usage. The need to inform mothers about the use of TCIM according to their health status is a matter that should be discussed [36], and it seems necessary for staff in health centers to ask all breastfeeding mothers about TCIM usage.

In our study, $39 \%$ of mothers who used TCIM believed that TCIM reported no side effects. Also, $51.9 \%$ considered complementary medicine to have minimal complications, and $99.8 \%$ of mothers who used herbal galactagogues during breastfeeding had experienced no side effects. According to a recent review, most mothers believe herbal medicines to be safer than chemical medicines [32]. Likewise, most mothers in Italy held that herbal medicines are safe and low-risk [28]. This is while herbal medicine is not completely harmless. For example, fennel, which has been introduced as a galactagogues in several studies, can lead to photosensitivity, dermatitis, diarrhea, and estrogenic effects. Due to the possibility of cross-allergenicity, mothers who are allergic to products of the Apiaceae family (e.g., carrots and celery) must avoid using fennel $[17,28,37]$.

Although the risk of complications is higher in the breastfeeding mother, the infant may also experience adverse effects following the use of herbal medicine by the mother [17]. Therefore, medical staff should 
discuss the effectiveness and side effects of TCIM with breastfeeding mothers, and the safety and effectiveness of TCIM products should be evaluated [27]. In fact, some studies have shown that mothers themselves desire to be provided with further information about TCIM $[2,36]$.

Numerous studies have been performed on galactagogues, though in many cases the studies have not been sufficiently valid or have not used an appropriate method [17, 38]. In galactagogues, like other TCIM drugs, we must consider contaminations and effective substances. Standardization and the development of pure herbal products are also important, and their safety should be checked against the Generally Recognized As Safe list $[17,39]$. Despite the fact that $59.5 \%$ of breastfeeding mothers in our study reported that the use of galactagogues had led to a definite increase in breast milk and although side effects were reported in only 2 cases, about $60 \%$ of mothers who used TCIM during breastfeeding believed that TCIM galactagogues could not be recommended to all mothers. According to the literature, this lack of recommendation may be due to the low efficacy of TCIM or the possibility of adverse effects [40]. The effects of past TCIM usage and a higher number of past deliveries should also not be overlooked, where our multivariable regression analysis showed that these two factors boost the chance of choosing to use TCIM by approximately $80 \%$ and $60 \%$, respectively.

According to our findings, the most commonly used herbal medicines among breastfeeding mothers were mint, fennel, thyme, and chamomile, with the predominant reason of usage being to induce lactation. In the US study, chamomile and cranberry were most widely used among mothers following childbirth, while the Italian study revealed fennel, licorice, and aloe to be the most commonly used herbal products [25, 28]. In Australia, the plants most widely used during breastfeeding were fenugreek and ginger.

Furthermore, chamomile was used is $7.2 \%$ of cases, predominantly for relaxation purposes, while $4.9 \%$ of breastfeeding mothers reported the use of fennel for increasing their milk and minimizing infantile colic [2]. The most common non-herbal medicine used by breastfeeding mothers in our study was iron supplements (24\%). In the US study, omega- 3 was found to be the predominantly used supplement among postpartum mothers (6.6\%) [25]. This difference can be due to culture dissimilarities and variations in the availability, affordability, and the method of use of these products in different countries and regions.

Among the plants that were used for more than 10 days were garlic and senna, which should be avoided during breastfeeding according to the references of PM. Rhazes states that plants that have a cold and dry or very hot temperament reduce breast milk [41], though some studies have revealed that garlic and senna can increase breast milk [42]. In the studies of Bazzano et al. and Nice et al., garlic was included in the list of common herbal galactagogues $[43,44]$. On the other hand, Mennella et al. used garlic capsules and placebos in their study and found no significant differences in lactation between the intervention and control groups, with infantile colic being reported as an adverse effect in both groups [45]. Another study showed that garlic can alter the smell of milk, thereby making it undesirable for the infant. In the study by Nice et al., it was noted that garlic can prolong the duration of breastfeeding but can also cause discontinuation if it is inappropriate for the infant [44]. It seems that studies on the use of these two herbs 
during breastfeeding are contradictory, meaning that the advice of PM scholars to avoid their long-term use (more than 10 days) is perhaps reasonable.

In the present work, the study population was mothers who referred to government health centers, who may differ in terms of demographic characteristics from those who attend private health sector.

Nonetheless, it should be noted that the majority of Iranian mothers refer to government health centers during breastfeeding. On the other hand, our findings are based on data obtained using a structured interview, where the possibility of inaccurate responses from the mothers cannot be overlooked. One of the strengths of our work is the use of multivariable regression analysis, which removes the effects of confounding factors.

\section{Conclusions}

The present study showed the high prevalence of TCIM usage among breastfeeding mothers in Shiraz as a sample of the Iranian population. Various factors influenced the volume and type of TCIM products used, the most important of which were literacy, employment, number of deliveries, and past TCIM use. We recommend the conduction of similar studies in nearby countries in order to establish a comprehensive comparison, thereby facilitating health policymaking. Furthermore, such data would allow us to design accurate, evidence-based clinical trials to determine the effectiveness and safety of TCIM products in breastfeeding women.

\section{List Of Abbreviations}

World Health Organization WHO

Persian Medicine PM

Standard deviation SD

Odds ratio $O R$

Confidence interval $\mathrm{Cl}$

Age-standardized prevalence ASP

Traditional, complementary, and integrative medicine TCIM

\section{Declarations}

\section{Ethics approval and consent to participate}

Women who willingly signed the written consent forms were enrolled into the study. This study was approved by Ethics Approval Committee of Shiraz University of Medical Sciences 


\section{Consent for publication}

Not applicable.

\section{Availability of data and materials}

The datasets used and/or analyzed during the current study are available from the corresponding author on reasonable request.

\section{Competing interests}

The authors declare that they have no competing interests.

\section{Funding}

Not applicable.

\section{Authors' contributions}

Conceptualization: HMV and MP. Methodology: HMV, ZS, and MP. Data Curation: ZS, FA, and MP. Formal Analysis: HMV, ZS and MP. Investigation: ZS, HC and MP. Writing - Original Draft: HMV, ZS, FA, HC, and MP. Writing - Review \& Editing: HMV, HC, and MP. Supervision: HMV and MP. All authors have read and approved the final manuscript.

\section{References}

1. Arora S, McJunkin C, Wehrer J, Kuhn P: Major factors influencing breastfeeding rates: Mother's perception of father's attitude and milk supply. Pediatrics 2000;106:E67.

2. Sim TF, Sherriff J, Hattingh HL, Parsons R, Tee LB: The use of herbal medicines during breastfeeding: a population-based survey in Western Australia. BMC Complement Altern Med 2013;13:317.

3. Grummer-Strawn LM, Zehner E, Stahlhofer M, Lutter C, Clark D, Sterken E, Harutyunyan S, Ransom El: New World Health Organization guidance helps protect breastfeeding as a human right. Matern Child Nutr 2017;13

4. Abrahams SW, Labbok MH: Breastfeeding and otitis media: a review of recent evidence. Curr Allergy Asthma Rep 2011;11:508-512. 
5. Rouw E, von Gartzen A, Weißenborn A: [The importance of breastfeeding for the infant]. Bundesgesundheitsblatt Gesundheitsforschung Gesundheitsschutz 2018;61:945-951.

6. Oddy WH, Sly PD, de Klerk NH, Landau LI, Kendall GE, Holt PG, Stanley FJ: Breast feeding and respiratory morbidity in infancy: a birth cohort study. Arch Dis Child 2003;88:224-228.

7. Mojalli M, Basiri Moghadam M, Shamshiri M: Effectiveness of Instructional Environment and Related Factors on Breastfeeding Function of Mothers. Horizon Med Sci 2010;16:59-64.

8. Del Ciampo LA, Del Ciampo IRL: Breastfeeding and the Benefits of Lactation for Women's Health. Rev Bras Ginecol Obstet 2018;40:354-359.

9. Noel-Weiss J, Bassett V, Cragg B: Developing a prenatal breastfeeding workshop to support maternal breastfeeding self-efficacy. J Obstet Gynecol Neonatal Nurs 2006;35:349-357.

10. Labbok MH, Clark D, Goldman AS: Breastfeeding: maintaining an irreplaceable immunological resource. Nat Rev Immunol 2004;4:565-572.

11. Brockway M, Benzies K, Hayden KA: Interventions to Improve Breastfeeding Self-Efficacy and Resultant Breastfeeding Rates: A Systematic Review and Meta-Analysis. J Hum Lact 2017;33:486499.

12. Organization WH: WHO traditional medicine strategy: 2014-2023. World Health Organization, 2013.

13. Organization WH: National policy on traditional medicine and regulation of herbal medicines: Report of a WHO global survey. World Health Organization, 2005.

14. Morns M, Bowman D, Steel A: Breastfeeding difficulties: The role of integrative medicine (IM) in breastfeeding support. Adv Integr Med 2019;6:3-4.

15. Jackson PC: Complementary and alternative methods of increasing breast milk supply for lactating mothers of infants in the NICU. Neonatal Netw 2010;29:225-230.

16. James PB, Kaikai Al, Bah AJ, Steel A, Wardle J: Herbal medicine use during breastfeeding: a crosssectional study among mothers visiting public health facilities in the Western area of Sierra Leone. BMC Complement Altern Med 2019;19:66.

17. Anderson PO: Herbal Use During Breastfeeding. Breastfeed Med 2017;12:507-509.

18. Gabay MP: Galactogogues: medications that induce lactation. J Hum Lact 2002;18:274-279.

19. Sim TF, Hattingh HL, Sherriff J, Tee LB: Perspectives and attitudes of breastfeeding women using herbal galactagogues during breastfeeding: a qualitative study. BMC Complement Altern Med 2014;14:216.

20. Buntuchai G, Pavadhgul P, Kittipichai W, Satheannoppakao W: Traditional Galactagogue Foods and Their Connection to Human Milk Volume in Thai Breastfeeding Mothers. J Hum Lact 2017;33:552559.

21. Tang L, Lee AH, Binns CW, Hui YV, Yau KKW: Consumption of Chinese herbal medicines during pregnancy and postpartum: A prospective cohort study in China. Midwifery 2016;34:205-210.

22. Avicenna: Qanun fi al Tib [Canon of Medicine]. Beirut, Ehyaol Toras al-Arabi Press 2015. 
23. Jorjani E: Zakhireye Kharazm Shahi (Treasure of Kharazm Shah) Tehran, Iranian Medical Academy, 2001.

24. Aghili Shirazi MH: Makhzan ol-Adviya (Pharmaceutical treasures) [Persian]. Tehran, The Institute for Medical History-Islamic and Complementary Medicine, Iran University of Medical Sciences, 2008.

25. Budzynska K, Filippelli AC, Sadikova E, Low Dog T, Gardiner P: Use and Factors Associated With Herbal/Botanical and Nonvitamin/Nonmineral Dietary Supplements Among Women of Reproductive Age: An Analysis of the Infant Feeding Practices Study II. J Midwifery Womens Health 2016;61:419426.

26. Dalili H, Shariat M, Nayeri F, Emami Z, Sahebi R, Sahebi L: Duration of Breastfeeding and MaternalRelated Factors in Iran, Systematic Review and Meta-Analysis. J Pediatr Nurs 2020;54:e23-e30.

27. Chuang $\mathrm{CH}$, Chang PJ, Hsieh WS, Tsai YJ, Lin SJ, Chen PC: Chinese herbal medicine use in Taiwan during pregnancy and the postpartum period: a population-based cohort study. Int J Nurs Stud 2009;46:787-795.

28. Aleandri V, Bertazzoni G, Romanzi D, Vetrano G, Durazzi F, Mazzanti G, Vitalone A: The use of herbal products during breastfeeding: a study from a public Italian hospital. J Food Process Technol 2014;5:1.

29. Oldendick R, Coker AL, Wieland D, Raymond JI, Probst JC, Schell BJ, Stoskopf CH: Population-based survey of complementary and alternative medicine usage, patient satisfaction, and physician involvement. South Carolina Complementary Medicine Program Baseline Research Team. South Med J 2000;93:375-381.

30. Shaikh U, Ahmed O: Islam and infant feeding. Breastfeed Med 2006;1:164-167.

31. Zareai M, O'Brien ML, Fallon AB: Creating a breastfeeding culture: a comparison of breastfeeding practises in Australia and Iran. Breastfeed Rev 2007;15:15-20.

32. Zheng $\mathrm{T}$, Chen $\mathrm{W}, \mathrm{Hu} \mathrm{H}$, Wang $\mathrm{Y}$, Harnett JE, Ung COL: The prevalence, perceptions and behaviors associated with traditional/complementary medicine use by breastfeeding women living in Macau: a cross-sectional survey study. BMC Complement Med Ther 2020;20:122.

33. Othman N, Lamin RAC, Othman CN: The Malay Mothers' Perspective on the Usage of Galactagogue. J Asian Behaviour Studies 2018;3:159-167.

34. Frass M, StrassI RP, Friehs H, Müllner M, Kundi M, Kaye AD: Use and acceptance of complementary and alternative medicine among the general population and medical personnel: a systematic review. Ochsner J 2012;12:45-56.

35. Bordbar M, Pasalar M, Safaei S, kamfiroozi R, Zareifar S, zekavat O, Haghpanah S: Complementary and alternative medicine use in thalassemia patients in Shiraz, southern Iran: A cross-sectional study. J Tradit Complement Med 2018;8:141-146.

36. Barnes LAJ, Barclay L, McCaffery K, Aslani P: Complementary medicine products informationseeking by pregnant and breastfeeding women in Australia. Midwifery 2019;77:60-70.

37. Zapantis A, Steinberg JG, Schilit L: Use of herbals as galactagogues. J Pharm Pract 2012;25:222231. 
38. Mortel M, Mehta SD: Systematic review of the efficacy of herbal galactogogues. J Hum Lact 2013;29:154-162.

39. Burdock GA, Carabin IG: Generally recognized as safe (GRAS): history and description. Toxicol Lett 2004;150:3-18.

40. Zheng T, Yao D, Chen W, Hu H, Ung COL, Harnett JE: Healthcare providers' role regarding the safe and appropriate use of herbal products by breastfeeding mothers: A systematic literature review. Complement Ther Clin Pract 2019;35:131-147.

41. Razi MZ: Al-Havi Fi Al-Tibb (Arabic). Beirut, Dar Al Kotob Al-islmiyah, 2000.

42. Budzynska K, Gardner ZE, Dugoua JJ, Low Dog T, Gardiner P: Systematic review of breastfeeding and herbs. Breastfeed Med 2012;7:489-503.

43. Bazzano AN, Hofer R, Thibeau S, Gillispie V, Jacobs M, Theall KP: A Review of Herbal and Pharmaceutical Galactagogues for Breast-Feeding. Ochsner J 2016;16:511-524.

44. Nice FJ: Common Herbs and Foods Used as Galactogogues. Infant Child Adolescent Nut 2011;3:129132.

45. Mennella JA, Beauchamp GK: The effects of repeated exposure to garlic-flavored milk on the nursling's behavior. Pediatr Res 1993;34:805-808.

\section{Figures}

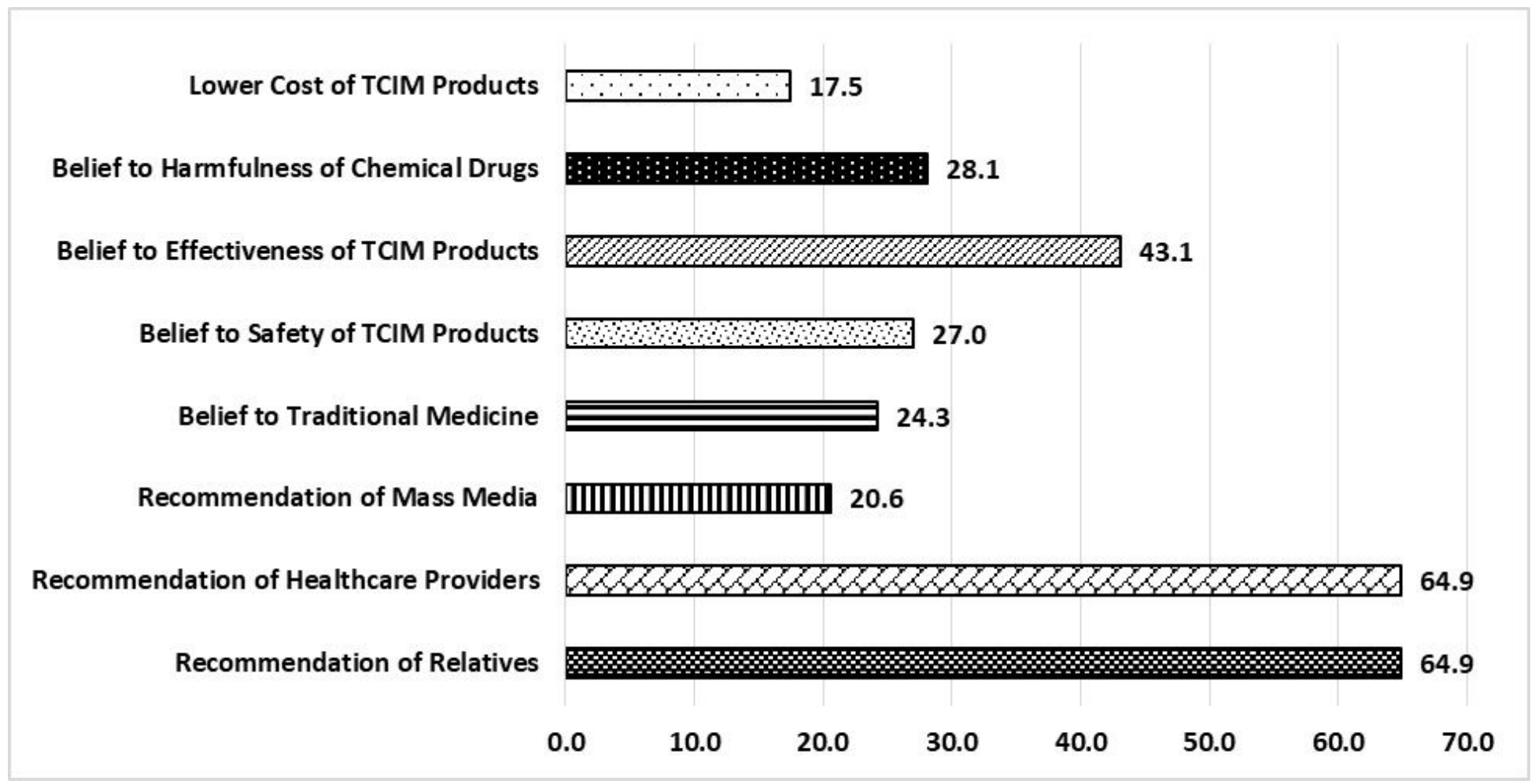

Figure 1 
Reasons for use of traditional, complementary, and integrative medicine (TCIM) products in lactating mothers (in percent)

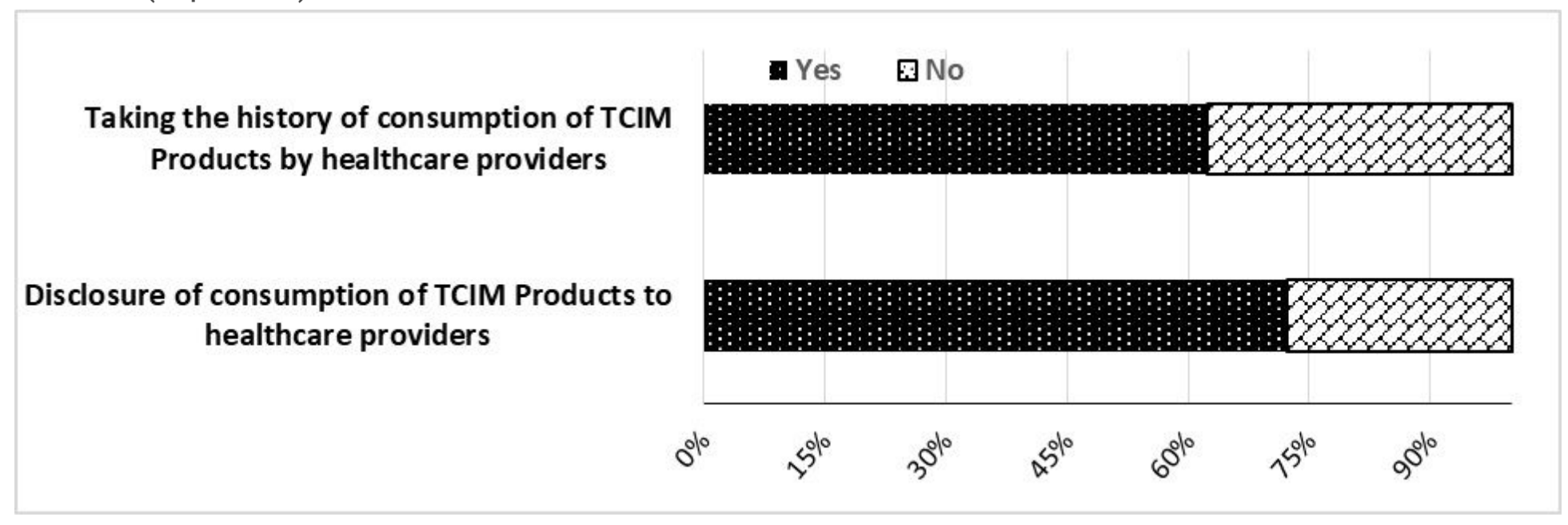

Figure 2

Participants' disclosure and healthcare provider's report about the traditional, complementary, and integrative medicine (TCIM) products use during breastfeeding 


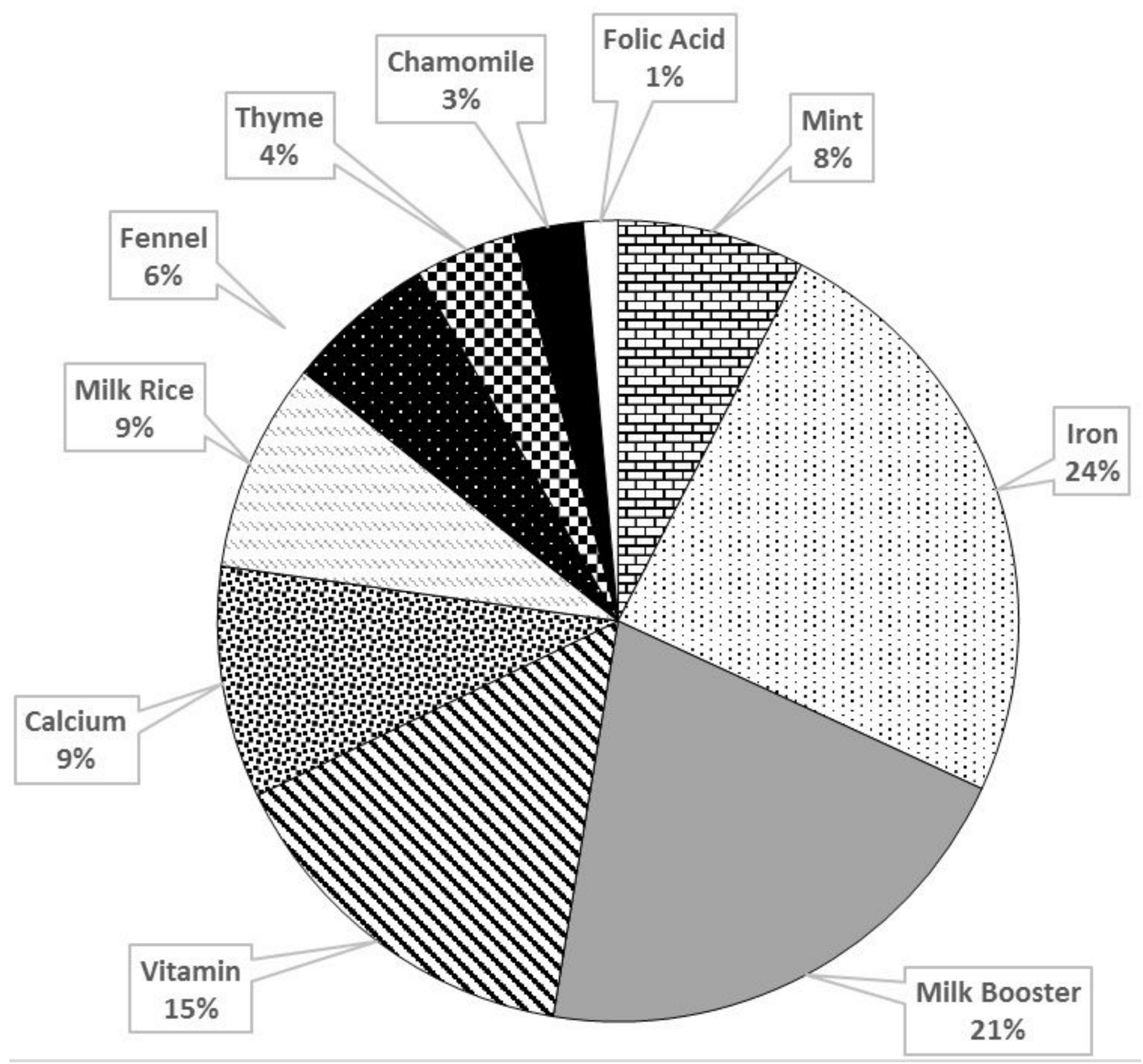

Figure 3

Participants' distribution of the traditional, complementary, and integrative medicine (TCIM) products use during breastfeeding

\section{Supplementary Files}

This is a list of supplementary files associated with this preprint. Click to download.

- STROBEchecklistcrosssectional.doc 